\title{
BMJ
}

\section{Duplex ultrasonography, magnetic resonance angiography, and computed tomography angiography for diagnosis and assessment of symptomatic, lower limb peripheral arterial disease: systematic review}

\author{
Ros Collins, research fellow, ${ }^{1}$ Jane Burch, research fellow, ${ }^{1}$ Gillian Cranny, research fellow, \\ Raquel Aguiar-Ibáñez, research fellow in health economics, ${ }^{1}$ Dawn Craig, research fellow in health \\ economics, ${ }^{1}$ Kath Wright, information officer, ${ }^{1}$ Elizabeth Berry, senior lecturer, ${ }^{2}$ Michael Gough, consultant \\ vascular surgeon, ${ }^{3}$ Jos Kleijnen, director, ${ }^{4}$ Marie Westwood senior research fellow
}

\begin{abstract}
${ }^{1}$ Centre for Reviews and Dissemination, University of York, York Y010 5DD

${ }^{2}$ Academic Unit of Medical Physics, University of Leeds, Leeds

${ }^{3}$ Leeds Teaching Hospitals $\mathrm{N}$ HS Trust, Leeds

${ }^{4}$ Kleijnen Systematic Reviews Ltd, York

Correspondence to: Ros Collins rc14@york.ac.uk
\end{abstract}

doi: 10.1136/bmi.39217.473275.55

\section{ABSTRACT}

Objectives To determine the diagnostic accuracy of duplex ultrasonography, magnetic resonance angiography, and computed tomography angiography, alone or in combination, for the assessment of lower limb peripheral arterial disease; to evaluate the impact of these assessment methods on management of patients and outcomes; and to evaluate the evidence regarding attitudes of patients to these technologies and summarise available data on adverse events. Design Systematic review.

Methods Searches of 11 electronic databases (to April 2005), six journals, and reference lists of included papers for relevant studies. Two reviewers independently selected studies, extracted data, and assessed quality. Diagnostic accuracy studies were assessed for quality with the QUADAS checklist.

Results 107 studies met the inclusion criteria; 58 studies provided data on diagnostic accuracy, one on outcomes in patients, four on attitudes of patients, and 44 on adverse events. Quality assessment highlighted limitations in the methods and quality of reporting. Most of the included studies reported results by arterial segment, rather than by limb or by patient, which does not account for the clustering of segments within patients, so specificities may be overstated. For the detection of stenosis of $50 \%$ or more in a lower limb vessel, contrast enhanced magnetic resonance angiography had the highest diagnostic accuracy with a median sensitivity of 95\% (range $92-99.5 \%$ ) and median specificity of $97 \%$ (64-99\%). The results were $91 \%$ (89-99\%) and 91\% (83$97 \%$ ) for computed tomography angiography and $88 \%$ (80-98\%) and 96\% (89-99\%) for duplex ultrasonography. A controlled trial reported no significant differences in outcomes in patients after treatment plans based on duplex ultrasonography alone or conventional contrast angiography alone, though in $22 \%$ of patients supplementary contrast angiography was needed to form a treatment plan. The limited evidence available suggested that patients preferred magnetic resonance angiography (with or without contrast) to contrast angiography, with half expressing no preference between magnetic resonance angiography or duplex ultrasonography (among patients with no contraindications for magnetic resonance angiography, such as claustrophobia). Where data on adverse events were available, magnetic resonance angiography was associated with the highest proportion of adverse events, but these were mild. The most severe adverse events, although rare, were mainly associated with contrast angiography.

Conclusions Contrast enhanced magnetic resonance angiography seems to be more specific than computed tomography angiography (that is, better at ruling out stenosis over $50 \%$ ) and more sensitive than duplex ultrasonography (that is, better at ruling in stenosis over $50 \%$ ) and was generally preferred by patients over contrast angiography. Computed tomography angiography was also preferred by patients over contrast angiography; no data on patients' preference between duplex ultrasonography and contrast angiography were available. Where available, contrast enhanced magnetic resonance angiography might be a viable alternative to contrast angiography.

\section{INTRODUCTION}

Lower limb peripheral arterial disease is the atheromatous narrowing or occlusion of an artery or arteries of the leg. If symptoms occur these may include intermittent claudication, ischaemic rest pain, ulceration, and gangrene. ${ }^{1}$ Risk factors include advanced age, smoking, hypertension, hyperlipidaemia, diabetes, obesity, and family history. ${ }^{2}$ Management strategies differ for patients with intermittent claudication (often conservative management, with radiological or surgical intervention reserved for patients with reduced quality of life) and patients with limb threatening ischaemia, in whom angioplasty, surgical revascularisation, or amputation are usually required. ${ }^{3}$ The choice of intervention is governed by the severity of the disease and may involve 
Titles and abstracts identified and screened $(n=8590)$

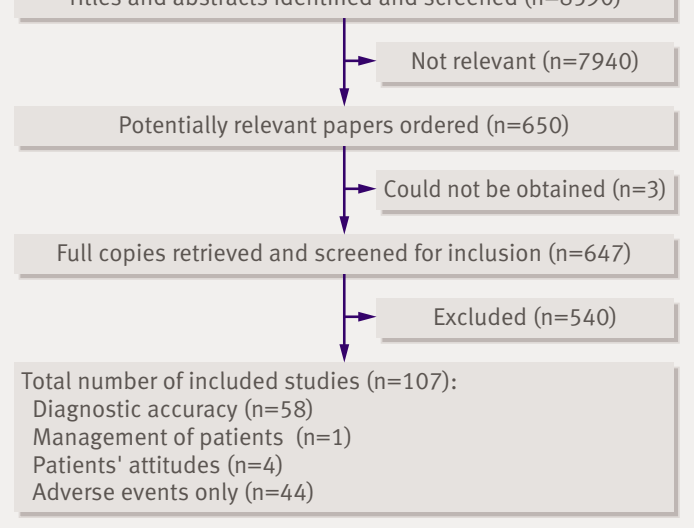

Fig 1 | Flow chart of studies through review process

combined treatments. Thus patients with limb threatening ischaemia require a detailed assessment for a suitable treatment plan to be developed.

Intra-arterial contrast angiography is regarded as the reference standard. The drawbacks are those associated with arterial puncture, ionising radiation, and potential nephrotoxicity of iodinated contrast agents. Several alternative imaging techniques are available, including magnetic resonance angiography, computed tomography angiography and duplex ultrasonography. These techniques are less invasive than contrast angiography, although computed tomography angiography carries risks relating to ionising radiation, and both contrast enhanced magnetic resonance angiography and computed tomography angiography carry risks associated with the use of contrast agents.

We carried out a systematic review to examine the evidence regarding the performance of magnetic resonance angiography, computed tomography angiography, and duplex ultrasonography as alternatives to contrast angiography to try to identify a technique that is safer and more acceptable to patients but as effective as contrast angiography for the assessment of symptomatic peripheral arterial disease. Here we present the systematic review of the evidence on effectiveness. The full report with economic evaluation is available elsewhere.

\section{METHODS}

We searched 11 databases (Medline, Embase, BIOS IS Previews, Science Citation Index, NTIS Database, LILACS, SIGLE (system for information on grey literature in Europe), Dissertation Abstracts Online, Inside Conferences, Pascal from 1996 to April 2005, and the Cochrane Database of Systematic Reviews, Issue 3, 2005), six key journals on imaging and vascular disease, and reference lists of included studies for published and unpublished data. No language restrictions were applied. Electronic searches were not limited by study design. Two reviewers conducted each stage of the review process (except in the case of foreign language studies), with disagreements resolved by consensus or referral to a third reviewer. Full details of the review methods, including the search strategies, are described elsewhere. ${ }^{4}$ Table 1 presents the inclusion criteria for each section of the review.

We used the QUADAS checklist to assess the quality of diagnostic accuracy studies. ${ }^{5}$ The results of diagnostic accuracy studies were analysed according to the imaging tests assessed (magnetic resonance angiography, computed tomography angiography, or duplex ultrasonography). Magnetic resonance angiography technologies were further grouped by specific technique (2D phase contrast, 2D time of flight, or contrast enhanced). We derived the sensitivity and specificity for the detection of stenosis in arterial segments from the $2 \times 2$ tables reported in each study. To account for values of zero in the $2 \times 2$ tables, we added 0.5 to all cells. ${ }^{6}$ Heterogeneity was assessed with the Q statistic

\begin{tabular}{|c|c|c|c|c|}
\hline & Diagnostic accuracy & $\begin{array}{l}\text { Impact on patient } \\
\text { management/outcome }\end{array}$ & Acceptability for patients & Adverse events \\
\hline Study design & $\begin{array}{l}\text { Diagnostic cohort or case- } \\
\text { control }\end{array}$ & $\begin{array}{l}\text { Randomised controlled trial/ } \\
\text { controlled clinical trial }\end{array}$ & $\begin{array}{l}\text { Studies of any design, } \\
\text { excluding case reports }\end{array}$ & $\begin{array}{l}\text { Studies of any design, } \\
\text { excluding case reports }\end{array}$ \\
\hline Population & $\begin{array}{l}\text { Studies in } \geq 20 \text { adults ( } \geq \\
18 \text { years) with symptoms } \\
\text { indicating lower limb } \\
\text { peripheral arterial disease }\end{array}$ & $\begin{array}{l}\text { Studies in } \geq 20 \text { adults ( } \geq \\
18 \text { years) with symptoms } \\
\text { indicating lower limb } \\
\text { peripheral arterial disease }\end{array}$ & $\begin{array}{l}\text { Studies in } \geq 20 \text { adults ( } \geq \\
18 \text { years) with symptoms } \\
\text { indicating lower limb } \\
\text { peripheral arterial disease }\end{array}$ & $\begin{array}{l}\text { Studies in adults with } \\
\text { symptoms indicating lower } \\
\text { limb peripheral arterial disease }\end{array}$ \\
\hline $\begin{array}{l}\text { Index tests/ } \\
\text { interventions }\end{array}$ & $\begin{array}{l}\text { Duplex ultrasonography, } \\
\text { magnetic resonance } \\
\text { angiography, or computed } \\
\text { tomography angiography, } \\
\text { alone or in combination }\end{array}$ & $\begin{array}{l}\text { Duplex ultrasonography, } \\
\text { magnetic resonance } \\
\text { angiography, or computed } \\
\text { tomography angiography, } \\
\text { alone or in combination }\end{array}$ & $\begin{array}{l}\text { Duplex ultrasonography, } \\
\text { magnetic resonance } \\
\text { angiography, or computed } \\
\text { tomography angiography, } \\
\text { alone or in combination }\end{array}$ & $\begin{array}{l}\text { Duplex ultrasonography, } \\
\text { magnetic resonance } \\
\text { angiography, or computed } \\
\text { tomography angiography, } \\
\text { alone or in combination }\end{array}$ \\
\hline Reference standard & $\begin{array}{l}\text { Intra-arterial contrast } \\
\text { angiography or findings at } \\
\text { surgery/follow-up }\end{array}$ & NA & NA & NA \\
\hline Outcome measures & $\begin{array}{l}\text { Sufficient information to } \\
\text { construct } 2 \times 2 \text { tables of test } \\
\text { performance }\end{array}$ & $\begin{array}{l}\text { Any treatment decision or long } \\
\text { term outcome measure (for } \\
\text { example, graft/vessel patency } \\
\text { after intervention, morbidity) }\end{array}$ & $\begin{array}{l}\text { Any reported criteria relating to } \\
\text { acceptability for patients }\end{array}$ & $\begin{array}{l}\text { Adverse events relating to index } \\
\text { test or to currently used contrast } \\
\text { agents }\end{array}$ \\
\hline
\end{tabular}


Table 2 | Diagnostic accuracy for detection of stenosis $50 \%$ or more or occlusion with different assessment methods

\begin{tabular}{|c|c|c|c|c|c|c|c|c|c|}
\hline \multirow[b]{2}{*}{ Study } & \multirow{2}{*}{$\begin{array}{c}\text { No of } \\
\text { patients }\end{array}$} & \multirow{2}{*}{$\begin{array}{l}\text { Fontaine stage } \\
\text { II/III/IV* (\%) }\end{array}$} & \multirow{2}{*}{$\begin{array}{c}\text { No of } \\
\text { segments }\end{array}$} & \multicolumn{2}{|c|}{$\begin{array}{l}\text { Positive } \\
\text { result }\end{array}$} & \multicolumn{2}{|c|}{$\begin{array}{l}\text { Negative } \\
\text { result }\end{array}$} & \multirow{2}{*}{$\begin{array}{c}\text { Sensitivity (\%) }(95 \% \\
\mathrm{Cl})\end{array}$} & \multirow{2}{*}{$\begin{array}{c}\text { Specificity (\%) (95\% } \\
\mathrm{CI})\end{array}$} \\
\hline & & & & True & False & False & True & & \\
\hline \multicolumn{10}{|c|}{ Contrast enhanced magnetic resonance angiography } \\
\hline Cronberg $^{\mathrm{w} 13}$ & 35 & $9 / 3 / 89$ & 418 & 227 & 62 & 20 & 109 & $91.9(87.8$ to 95.0$)$ & 63.7 (56.1 to 70.9$)$ \\
\hline Laissyw16 $^{\text {w16 }}$ & 20 & $100 / 0 / 0$ & 520 & 104 & 14 & 9 & 393 & $92.0(85.4$ to 96.3$)$ & 96.6 (94.3 to 98.1$)$ \\
\hline Lenhart $^{\mathrm{w} 17}$ & 45 & NR & 220 & 79 & 8 & 4 & 129 & 95.2 (88.1 to 98.7$)$ & $94.2(88.8$ to 97.4$)$ \\
\hline Schafer $^{\text {w19 }}$ & 30 & NR & 576 & 138 & 13 & 9 & 416 & 93.9 (88.7 to 97.2) & 97.0 (94.9 to 98.4$)$ \\
\hline Steffens ${ }^{\mathrm{w} 21}$ & 50 & NR & 900 & 185 & 8 & 1 & 706 & 99.5 (97.0 to 100$)$ & 98.9 (97.8 to 99.5$)$ \\
\hline Sueyoshiw22 $^{\text {22 }}$ & 23 & $83 / 17 / 0$ & 423 & 67 & 3 & 2 & 351 & 97.1 (89.9 to 99.6) & 99.2 (97.5 to 99.8) \\
\hline Winterer $^{\mathrm{w} 23}$ & 76 & $87 / 13 / 0$ & 1780 & 362 & 43 & 14 & 1361 & 96.3 (93.8 to 97.9$)$ & 96.9 (95.9 to 97.8$)$ \\
\hline \multicolumn{10}{|c|}{ 2D time of flight magnetic resonance angiography } \\
\hline Baum $^{\text {w2 }}$ & 155 & NR & 1188 & 527 & 101 & 100 & 460 & 84.1 (80.9 to 86.8$)$ & 82.0 (78.6 to 85.1$)$ \\
\hline Hochw6 $^{\text {w6 }}$ & 20 & NR & 544 & 161 & 37 & 44 & 302 & 78.5 (72.3 to 84.0$)$ & 89.1 (85.3 to 92.2) \\
\hline $\mathrm{Hoch}^{\mathrm{w7}}$ & 45 & $18 / 20 / 62$ & 352 & 172 & 13 & 12 & 155 & 93.5 (88.9 to 96.6$)$ & 92.3 (87.1 to 95.8$)$ \\
\hline Snidow $^{\text {w10 }}$ & 42 & NR & 378 & 80 & 76 & 7 & 215 & $92.0(84.1$ to 96.7$)$ & 73.9 (68.4 to 78.8$)$ \\
\hline Yucel $^{\mathrm{w} 12}$ & 25 & $0 / 84 / 16$ & 206 & 65 & 16 & 6 & 119 & 91.5 (82.5 to 96.8$)$ & 88.1 (81.5 to 93.1$)$ \\
\hline \multicolumn{10}{|c|}{ 2D phase contrast magnetic resonance angiography } \\
\hline Steffens ${ }^{\mathrm{w} 1}$ & 115 & $100 / 0 / 0$ & 253 & 229 & 5 & 5 & 14 & 97.9 (95.1 to 99.3$)$ & 73.7 (48.8 to 90.9$)$ \\
\hline \multicolumn{10}{|c|}{ Computed tomography angiography } \\
\hline Heuschmid $^{\text {w27 }}$ & 23 & $78 / 13 / 9$ & 568 & 133 & 40 & 16 & 379 & 89.3 (83.1 to 93.7) & 90.5 (87.2 to 93.1$)$ \\
\hline Martinw28 $^{\text {w28 }}$ & 41 & NR & 1312 & 327 & 61 & 38 & 886 & 89.6 (86.0 to 92.5) & 93.6 (91.8 to 95.0) \\
\hline Puls ${ }^{\text {w30 }}$ & 31 & $97 / 3 / 0$ & 186 & 56 & 17 & 7 & 106 & 88.9 (78.4 to 95.4$)$ & 86.2 (78.8 to 91.7$)$ \\
\hline Rieker $^{\text {w31 }}$ & 50 & $74 / 12 / 14$ & 327 & 111 & 20 & 3 & 193 & 97.4 (92.5 to 99.5$)$ & 90.6 (85.9 to 94.2$)$ \\
\hline Catalanow26 $^{\text {w26 }}$ & 50 & $6 / 48 / 46$ & 1137 & 251 & 23 & 3 & 860 & 98.8 (96.6 to 99.8 ) & 97.4 (96.1 to 98.3 ) \\
\hline Portugaller $^{\text {w29 }}$ & 50 & $62 / 4 / 34$ & 740 & 240 & 80 & 21 & 399 & $92.0(88.0$ to 95.0$)$ & 83.3 (79.7 to 86.5$)$ \\
\hline \multicolumn{10}{|c|}{ Duplex ultrasonography } \\
\hline Alyw33 & 90 & $90 / 9 / 1$ & 3108 & 404 & 27 & 34 & 2643 & $92.2(89.3$ to 94.6$)$ & 99.0 (98.5 to 99.3$)$ \\
\hline Bergamini $^{\mathrm{w} 35}$ & 44 & NR & 404 & 94 & 13 & 24 & 273 & 79.7 (71.3 to 86.5$)$ & 95.5 (92.4 to 97.6$)$ \\
\hline Hatsukami $^{\text {w40 }}$ & 29 & NR & 243 & 73 & 6 & 12 & 152 & 85.9 (76.6 to 92.5$)$ & 96.2 (91.9 to 98.6) \\
\hline Linke $^{\text {w48 }}$ & 25 & $100 / 0 / 0$ & 134 & 41 & 4 & 2 & 87 & 95.3 (84.2 to 99.4$)$ & 95.6 (89.1 to 98.8$)$ \\
\hline Sensier $^{\mathrm{w} 50}$ & 76 & $88 / 0 / 12$ & 469 & 214 & 26 & 28 & 201 & 88.4 (83.7 to 92.2) & 88.5 (83.7 to 92.4) \\
\hline El-Kayaliw55 & 44 & NR & 357 & 123 & 15 & 3 & 216 & 97.6 (93.2 to 99.5$)$ & 93.5 (89.5 to 96.3$)$ \\
\hline Legemate $^{w 58}$ & 61 & $80 / 16 / 3$ & 918 & 179 & 30 & 33 & 676 & 84.4 (78.8 to 89.0$)$ & 95.8 (94.0 to 97.1$)$ \\
\hline
\end{tabular}

NR=not reported.

*Stage II=intermittent claudication; stage III=ischaemic rest pain; stage IV=tissue loss.

and graphically with forest plots. Most studies provided data for more than one anatomical area (above knee, below knee, foot) or more than one threshold of stenosis (50\%, 70\%, occlusion). The number of arterial segments assessed per patient and their anatomical distribution varied and was sometimes incompletely reported. Analyses were conducted with Meta-DiSc. ${ }^{7}$

We have presented a narrative synthesis for studies evaluating the impact of the method of assessment on management and outcome in patients, attitudes of patients, and studies of adverse events.

\section{RESULTS}

The search strategy generated 8590 references, of which 650 were considered to be potentially relevant; ultimately 107 met the inclusion criteria. Figure 1 shows the flow of studies through the selection process.

\section{Quality of diagnostic accuracy studies}

All included studies were diagnostic cohorts and were conducted in secondary or tertiary care settings. There were several potential sources of bias. Spectrum bias may have been present; over $70 \%$ of studies did not include an appropriate range of patients (defined as unselected, prospective adult patients with symptoms indicating lower limb peripheral arterial disease) or failed to provide sufficient details of the population; $48 \%$ of magnetic resonance angiography studies, $29 \%$ of computed tomography angiography studies, and $57 \%$ of duplex ultrasonography studies did not provide adequate details of selection criteria. Spectrum bias may underestimate or overestimate the accuracy of a test by investigating a selected population with regard to the severity of disease, demographics, or comorbidity. ${ }^{5}$ Bias may occur when the delay between the index test and reference standard are long enough for the disease to have progressed naturally; $20 \%$ of magnetic resonance angiography studies, 29\% of computed tomography angiography studies, and $36 \%$ of duplex ultrasonography studies did not report having less than a one month interval between the index test and reference standard. Bias may also occur when the 
results of the index test are interpreted by someone with prior knowledge of the results of the reference test and vice versa. The index test results were interpreted without knowledge of the reference test results in $84 \%$ of magnetic resonance angiography studies and $71 \%$ of duplex ultrasonography and computed tomography angiography studies. The reference test results were interpreted without knowledge of the index test results in $84 \%$ of magnetic resonance angiography studies, $82 \%$ of duplex ultrasonography studies, and $71 \%$ of computed tomography angiography studies.

There is evidence that the availability of appropriate clinical data increases the accuracy of interpretation. ${ }^{8}$ The availability of clinical data was poorly reported, with only one study that evaluated magnetic resonance angiography and duplex ultrasonography reporting that clinical data were available when the imaging results were interpreted. Full details of included studies and quality assessment are on www.york.ac.uk/inst/ $\mathrm{crd} /$ projects/peripheralarterialdisease.htm.

\section{Assessment of stenosis/occlusion}

Fifty eight diagnostic accuracy studies met the inclusion criteria. One evaluated 2D phase contrast

\begin{tabular}{l} 
Contrast enhanced magnetic resonance imaging \\
Cronberg \\
Laissy \\
Lenhart \\
Schafer \\
Steffens \\
Sueyoshi \\
Winterer \\
2D time of flight magnetic resonance imaging \\
Baum \\
Hoch \\
Hoch \\
Snidow \\
Yucel \\
2D phase contrast magnetic resonance imaging \\
Steffens \\
Computed tomography angiography \\
Heuschmid \\
Martin \\
Puls \\
Rieker \\
Catalano \\
Portugaller \\
Duplex ultrasonography \\
Aly \\
Bergamini \\
Hatsukami \\
Linke \\
Sensier \\
El-Kayali \\
Legemate \\
\hline
\end{tabular}

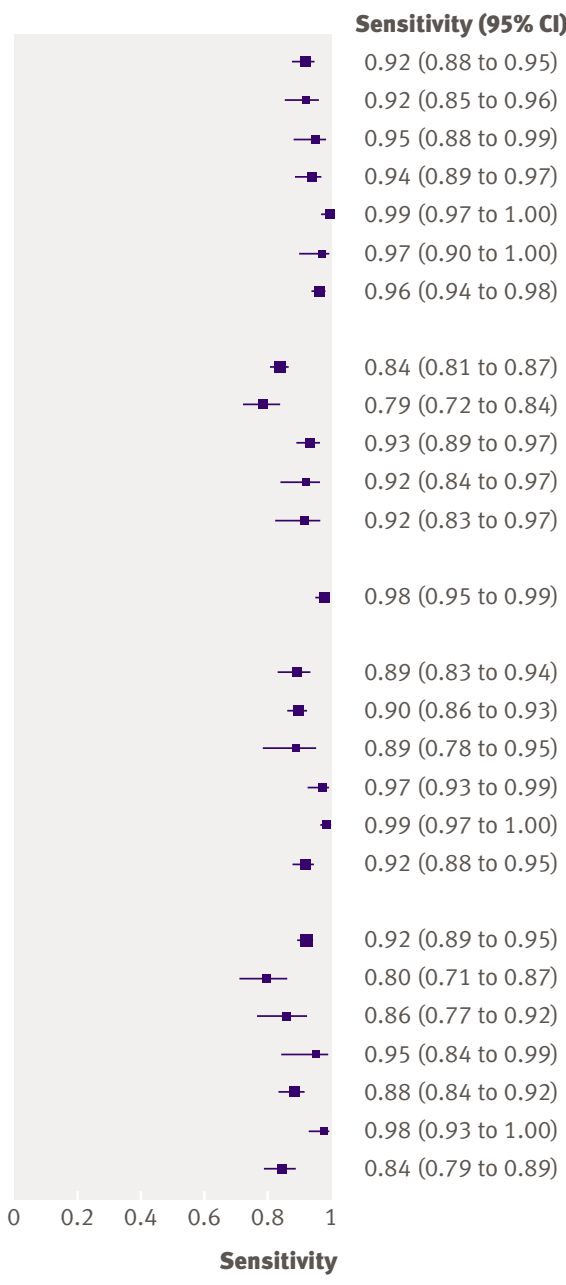

Fig 2 | Sensitivities for the detection of stenosis $\geq 50 \%$ or occlusion magnetic resonance angiography, ${ }^{\mathrm{w} 1} 11$ evaluated $2 \mathrm{D}$ time of flight magnetic resonance angiography, ${ }^{\text {w2-w12 }}$ 14 evaluated contrast enhanced magnetic resonance angiography, ${ }^{\text {w8 }}$ w13-w25 7 evaluated computed tomography angiography, ${ }^{\text {w26-w32 }}$ and 28 evaluated duplex ultrasonography. ${ }^{\text {w4 w8 w33-w58 }}$ No studies evaluated 3D time of flight magnetic resonance angiography. Contrast angiography was the reference standard in all studies. As there was significant heterogeneity between individual studies we did not pool data and have presented results as medians (range).

Most of the included studies reported results by arterial segment, rather than by limb or by patient, which does not account for the clustering of segments within patients. Therefore, the increased number of segments assessed is likely to increase the number of true negative test results, and thus the specificities may be overstated. We report results only for studies where data were reported by arterial segment. Full diagnostic accuracy results are available elsewhere. ${ }^{4}$

\section{Whole leg}

Table 2 shows data for detection of stenosis $50 \%$ or more or occlusion. Figures 2 and 3 show sensitivity and specificity data, respectively. Contrast enhanced magnetic resonance angiography had the highest diagnostic accuracy (seven studies ${ }^{\text {w13 }}$ w16 w17 w19 w21-w23), with median sensitivity 95\% (range 92-99.5\%) and median specificity $97 \%$ (64-99\%). One study had a low specificity $(64 \%)$ compared with the others; this was the only study to include assessment of foot vessels in the scan. ${ }^{\text {w13 }} 2 \mathrm{D}$ time of flight magnetic resonance angiography was less accurate (five studies ${ }^{\text {w2 }}$ w6 w7 w10 w12), with median sensitivity $92 \%(79-94 \%)$ and median specificity $88 \%$ (74-92\%). The use of time of flight magnetic resonance angiography has largely been superseded by contrast enhanced magnetic resonance angiography. Only one study ${ }^{\mathrm{w} 1}$ evaluated $2 \mathrm{D}$ phase contrast magnetic resonance angiography and this reported sensitivity and specificity of $98 \%$ and $74 \%$, respectively.

Computed tomography angiography (six studies, ${ }^{\text {w26-w31 }}$ five of which used multidetector row computed tomography angiography) had median sensitivity 91\% (89-99\%) and median specificity $91 \%$ (8397\%). Duplex ultrasonography (seven

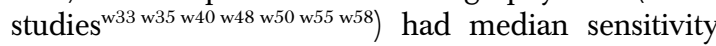
$88 \%(80-98 \%)$ and median specificity $96 \%(89-99 \%)$. The study with the lowest sensitivity $(80 \%)$ was the only study in this group with an unacceptable delay (that is, over one month) between the index test and reference standard. ${ }^{\text {w35 }}$

Table 3 shows data for detection of occlusion. Figures 4 and 5 show sensitivity and specificity data, respectively. Contrast enhanced magnetic resonance

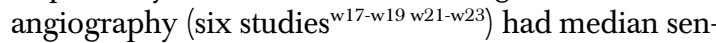
sitivity $94 \%(85-100 \%)$ and median specificity $99.2 \%$ (97-99.8\%). 2D time of flight magnetic resonance angiography (four studies ${ }^{\mathrm{w} 2} \mathrm{w6}$ w7, w12) had lower sensitivity; median 86\% (77-100\%) and comparable specificity; median 97\% (85-98\%). Computed tomography 


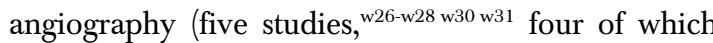
used multidetector row computed tomography angiography) had median sensitivity 97\% (89-100\%) and median specificity $99.6 \%$ (99-100\%).

Duplex ultrasonography (seven

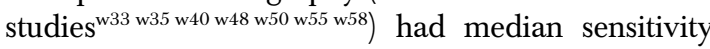
90\% (74-94\%), and median specificity 99\% (96$100 \%)$. One study reported a notably low sensitivity $(74 \%)^{\text {w48}}$; of the three studies that reported Fontaine classification (a system used to describe the severity of peripheral arterial disease), this was the only study restricted to people with Fontaine stage II (intermittent claudication).

\section{Above and below the knee}

Some studies provided separate results on diagnostic accuracy for arterial segments above and below the knee. The accuracy of the different techniques was similar for the detection of stenosis of $50 \%$ or more above and below the knee: with contrast enhanced magnetic resonance angiography the median sensitivity and specificity were $87 \%$ and $93 \%$, respectively, above the knee $\mathrm{e}^{\mathrm{w} 8 \mathrm{w} 14 \mathrm{w} 17 \mathrm{w} 20}$ and $83 \%$ and $92 \%$ below the $\mathrm{knee}^{\mathrm{w} 15 \mathrm{w} 17 \mathrm{w} 24}$; with duplex ultrasonography the

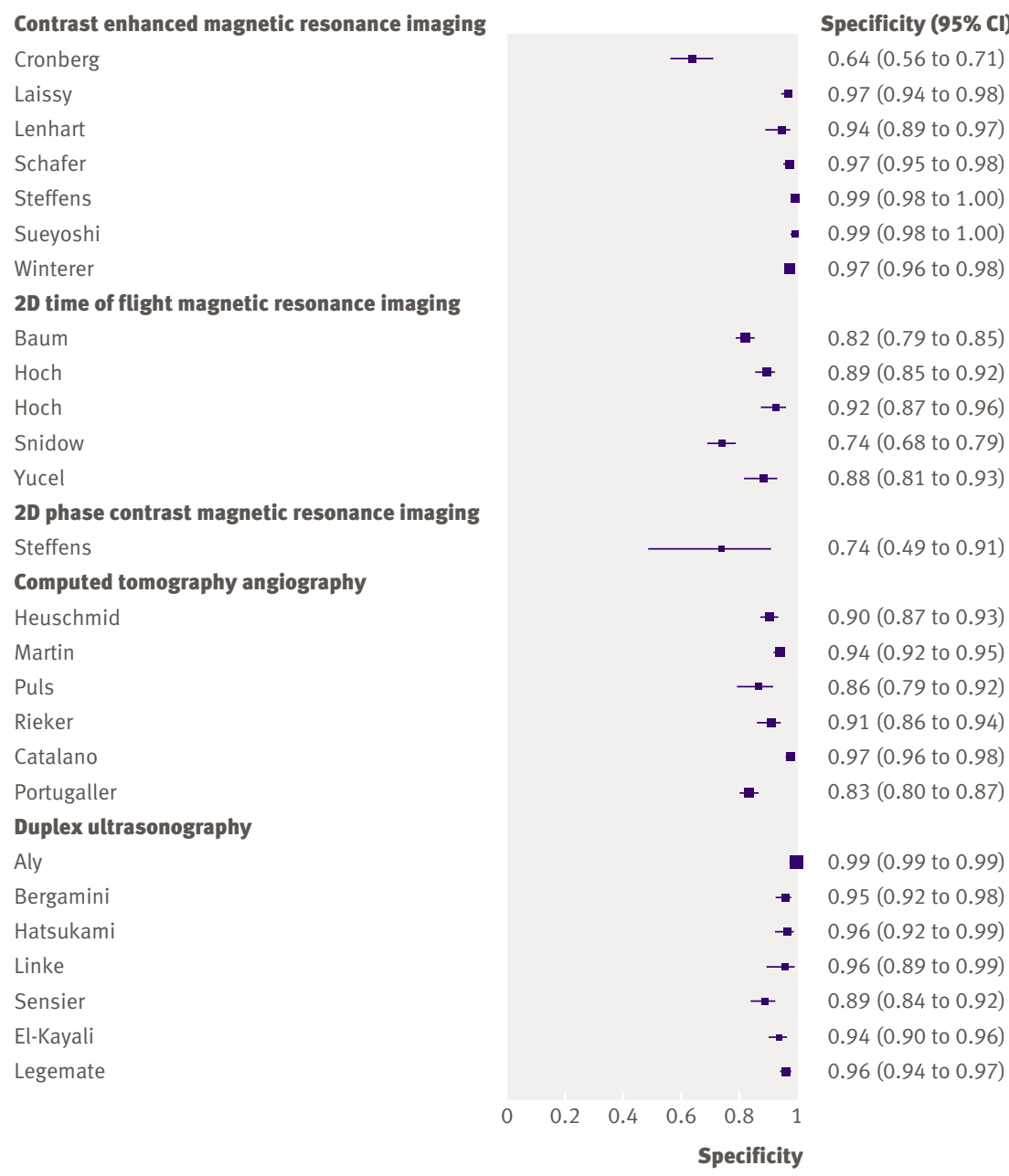

Fig $3 \mid$ Specificities for the detection of stenosis $\geq 50 \%$ or occlusion median sensitivity and specificity were $88 \%$ and $95 \%$ above the knee $\mathrm{w}^{\mathrm{w}} \mathrm{w} 35 \mathrm{w} 39 \mathrm{w} 40 \mathrm{w} 47 \mathrm{w} 55 \mathrm{w} 56$ and $84 \%$ and $93 \%$ below the knee. ${ }^{\text {w35 w40 w43 w55 }}$

Two studies assessed accuracy for the detection of occlusion in the foot: one evaluated 2D time of flight magnetic resonance angiography ${ }^{\mathrm{w} 5}$ and the other contrast enhanced magnetic resonance angiography. ${ }^{\text {w24 }}$ Sensitivities were $86 \%$ and $79 \%$, respectively, and specificities $27 \%$ and $86 \%$, respectively. One study assessed the accuracy of duplex ultrasonography for detecting target vessels suitable for surgery in the foot, with sensitivity and specificity of $64 \%$ and $80 \%$ respectively. ${ }^{\mathrm{w} 42}$ Although there was limited evidence, these data suggest that these techniques may be less accurate in the foot.

\section{Impact of method of assessment on management and} outcome

Only one controlled trial, a prospective assessment of duplex ultrasonography using a historical control group, met the inclusion criteria for assessing the impact of the assessment method on patients' management and outcome. ${ }^{\text {w59 }}$ The study included consecutive patients with lower leg ischaemia whose treatment plans were based on the results of either duplex ultrasonography with contrast angiography where indicated (114 patients) or contrast angiography (control group 113 patients).

In $78 \%$ of cases the management plan was based on duplex ultrasonography without the need for contrast angiography. There were no significant differences between the groups in terms of immediate and intermediate outcomes. This trial seems to have been well conducted and the results are likely to be reliable. As it used a historical control group, however, other factors occurring within the timeframe of the trial may have affected the results. Treatment and characteristics of patients were not significantly different between the two groups, although the authors did not comment on some factors that could have influenced outcomes, such as the graft material used, continuation of smoking, and the use of antiplatelet drugs.

\section{Patients' attitudes}

Four studies reported results relating to patients' attitudes. Two evaluated magnetic resonance angiography and contrast angiography, ${ }^{\text {w60 w61 }}$ one duplex ultrasonography and magnetic resonance angiography, ${ }^{\text {w62 }}$ and one computed tomography angiography, magnetic resonance angiography, and contrast angiography. ${ }^{\text {w63 }}$ Significantly more patients (28/30 patients) stated that they would prefer contrast enhanced magnetic resonance angiography over contrast angiography if they had to undergo testing again in the future, ${ }^{\text {w60 }}$ and contrast enhanced magnetic resonance angiography scored significantly better on a scale that rated patients' experience of the test compared with contrast angiography $(\mathrm{P}=0.0001$ and $\mathrm{P}=$ 0.0002). . 60 w61 $^{2}$

Contrast angiography was reported as the most uncomfortable, followed by contrast enhanced 
magnetic resonance angiography, with computed tomography angiography being the least uncomfortable $(\mathrm{P}=0.016) .{ }^{\text {w63 }}$ Fifty per cent of patients (who were not claustrophobic and had no metallic implants) had no preference between time of flight magnetic resonance angiography or duplex ultrasonography (49/ 98 patients). Of those who did express a preference, most preferred time of flight magnetic resonance angiography (40/49 patients). ${ }^{\text {w62 }}$

Within the same population there was no significant difference between time of flight magnetic resonance angiography and duplex ultrasonography on a scale that rated how "bothersome" the tests were. ${ }^{\text {w62 }}$ While some of the surveys potentially suffered from recall or sequential bias, they were generally well conducted and the results are probably reliable. As the studies included only patients who were suitable for magnetic resonance angiography, the results cannot be generalised to patients who are not suitable for magnetic resonance angiography, such as those with claustrophobia or metallic implants.

\section{Adverse events}

Nine of the diagnostic accuracy

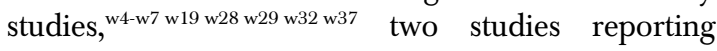
patient attitudes, ${ }^{\text {w60 w62 }}$ and 44 additional studies, w64-w107 reported results relating to adverse events. The lack of reporting of data on adverse events cannot be interpreted as no adverse events having occurred. The criteria used in monitoring and recording adverse events varied and were not always reported. These results should therefore be regarded only as a guide to the spectrum of adverse events reported and not as an accurate assessment of their frequency.

The most commonly reported adverse events were minor pain or discomfort during or immediately after the procedure $(17 \%$ for $2 \mathrm{D}$ time of flight magnetic resonance angiography (2/12 patients), $22 \%$ for duplex ultrasonography (22/98 patients), and up to $10 \%$ for contrast enhanced magnetic resonance angiography (10/98 patients)), acute symptoms in the digestive system associated with contrast enhanced magnetic resonance angiography (up to 10\% (2/20) patients), anxiety associated with $2 \mathrm{D}$ time of flight magnetic resonance angiography (10\% (4/40) patients), and acute adverse events in the central and peripheral nervous system associated with contrast enhanced magnetic resonance angiography (up to $10 \%$ (2/20) patients).

The highest proportion of adverse events was reported for magnetic resonance angiography. Major adverse events (death and severe vascular adverse events), however, were reported in a higher proportion

\begin{tabular}{|c|c|c|c|c|c|c|c|c|c|}
\hline \multirow[b]{2}{*}{ Study } & \multirow{2}{*}{$\begin{array}{c}\text { No of } \\
\text { patients }\end{array}$} & \multirow{2}{*}{$\begin{array}{c}\text { Fontaine stage } \\
\text { II/III/IV* (\%) }\end{array}$} & \multirow{2}{*}{$\begin{array}{c}\text { No of } \\
\text { segments }\end{array}$} & \multicolumn{2}{|c|}{$\begin{array}{l}\text { Positive } \\
\text { result }\end{array}$} & \multicolumn{2}{|c|}{$\begin{array}{l}\text { Negative } \\
\text { result }\end{array}$} & \multirow{2}{*}{$\begin{array}{c}\text { Sensitivity (\%) (95\% } \\
\mathrm{Cl})\end{array}$} & \multirow{2}{*}{$\begin{array}{c}\text { Specificity (\%) }(95 \% \\
\mathrm{Cl})\end{array}$} \\
\hline & & & & True & False & False & True & & \\
\hline \multicolumn{10}{|c|}{ Contrast enhanced magnetic resonance angiography } \\
\hline Lenhart $^{\mathrm{w} 17}$ & 45 & NR & 220 & 54 & 2 & 4 & 160 & $93.1(83.3$ to 98.1$)$ & 98.8 (95.6 to 99.9$)$ \\
\hline Meaney $^{\text {w18 }}$ & 20 & $100 / 0 / 0$ & 630 & 83 & 16 & 15 & 516 & 84.7 (76.0 to 91.2) & 97.0 (95.2 to 98.3$)$ \\
\hline Schafer $^{\text {w19 }}$ & 30 & NR & 576 & 72 & 1 & 5 & 498 & $93.5(85.5$ to 97.9$)$ & 99.8 (98.9 to 100$)$ \\
\hline Steffens $^{\mathrm{w} 21}$ & 50 & NR & 900 & 85 & 7 & 4 & 804 & 95.5 (88.9 to 98.8$)$ & 99.1 (98.2 to 99.7$)$ \\
\hline Sueyoshi $^{\text {w22 }}$ & 23 & $83 / 17 / 0$ & 423 & 39 & 1 & 0 & 383 & $100(91.0$ to 100$)$ & 99.7 (98.6 to 100) \\
\hline Winterer $^{\mathrm{w} 23}$ & 76 & $87 / 13 / 0$ & 1780 & 255 & 11 & 13 & 1501 & 95.1 (91.8 to 97.4) & 99.3 (98.7 to 99.6) \\
\hline \multicolumn{10}{|c|}{ 2D time of flight magnetic resonance angiography } \\
\hline Baumw2 $^{\text {w2 }}$ & 155 & NR & 1188 & 322 & 118 & 76 & 672 & 80.9 (76.7 to 84.6$)$ & 85.1 (82.4 to 87.5$)$ \\
\hline Hoch $^{\text {w6 }}$ & 20 & NR & 544 & 103 & 17 & 31 & 393 & 76.9 (68.8 to 83.7) & 95.9 (93.4 to 97.6$)$ \\
\hline Hochw7 $^{\text {w }}$ & 45 & $18 / 20 / 62$ & 352 & 101 & 4 & 11 & 236 & $90.2(83.1$ to 95.0$)$ & 98.3 (95.8 to 99.5$)$ \\
\hline Yucel $^{\text {w12 }}$ & 25 & $0 / 84 / 16$ & 206 & 40 & 4 & 0 & 162 & $100(91.2$ to 100$)$ & 97.6 (93.9 to 99.3$)$ \\
\hline \multicolumn{10}{|c|}{ Computed tomography angiography } \\
\hline Heuschmid $^{\text {w27 }}$ & 23 & $78 / 13 / 9$ & 568 & 49 & 6 & 5 & 508 & 90.7 (79.7 to 96.9) & 98.8 (97.5 to 99.6) \\
\hline Martin $^{\text {w28 }}$ & 41 & NR & 1312 & 202 & 2 & 26 & 1082 & $88.6(83.7$ to 92.4$)$ & 99.8 (99.3 to 100) \\
\hline Pulsw30 $^{\text {w30 }}$ & 31 & $97 / 3 / 0$ & 186 & 13 & 0 & 0 & 173 & $100(75.3$ to 100$)$ & $100(97.9$ to 100$)$ \\
\hline Riekerw31 $^{\text {w31 }}$ & 50 & $74 / 12 / 14$ & 327 & 61 & 1 & 1 & 264 & 98.4 (91.3 to 100$)$ & 99.6 (97.9 to 100$)$ \\
\hline Catalanow26 $^{\text {w26 }}$ & 50 & $6 / 48 / 46$ & 1137 & 170 & 5 & 5 & 957 & 97.1 (93.5 to 99.1) & 99.5 (98.8 to 99.8) \\
\hline \multicolumn{10}{|c|}{ Duplex ultrasonography } \\
\hline Aly $^{\text {w33 }}$ & 90 & $90 / 9 / 1$ & 3108 & 272 & 18 & 25 & 2793 & $91.6(87.8$ to 94.5$)$ & 99.4 (99.0 to 99.6) \\
\hline Bergamini $^{\text {w35 }}$ & 44 & NR & 404 & 76 & 10 & 13 & 305 & 85.4 (76.3 to 92.0) & 96.8 (94.2 to 98.5$)$ \\
\hline Hatsukami $^{\text {w0 }}$ & 29 & NR & 233 & 51 & 3 & 6 & 173 & 89.5 (78.5 to 96.0$)$ & 98.3 (95.1 to 99.6) \\
\hline Linke $^{\text {w48 }}$ & 25 & $100 / 0 / 0$ & 134 & 14 & 0 & 5 & 115 & 73.7 (48.8 to 90.9) & $100(96.8$ to 100$)$ \\
\hline Sensier $^{\text {w50 }}$ & 76 & $88 / 0 / 12$ & 469 & 166 & 11 & 21 & 271 & 88.8 (83.3 to 92.9) & 96.1 (93.1 to 98.0) \\
\hline Zeuchner $^{\text {w53 }}$ & 54 & NR & 322 & 50 & 3 & 3 & 266 & 94.3 (84.3 to 98.8) & 98.9 (96.8 to 99.8) \\
\hline Legemate $^{\text {w58 }}$ & 61 & $80 / 16 / 3$ & 918 & 103 & 6 & 9 & 800 & $92.0(85.3$ to 96.3$)$ & 99.3 (98.4 to 99.7 ) \\
\hline
\end{tabular}

$\mathrm{NR}=$ not reported

*Stage II=intermittent claudication; stage III=ischaemic rest pain; stage IV=tissue loss. 


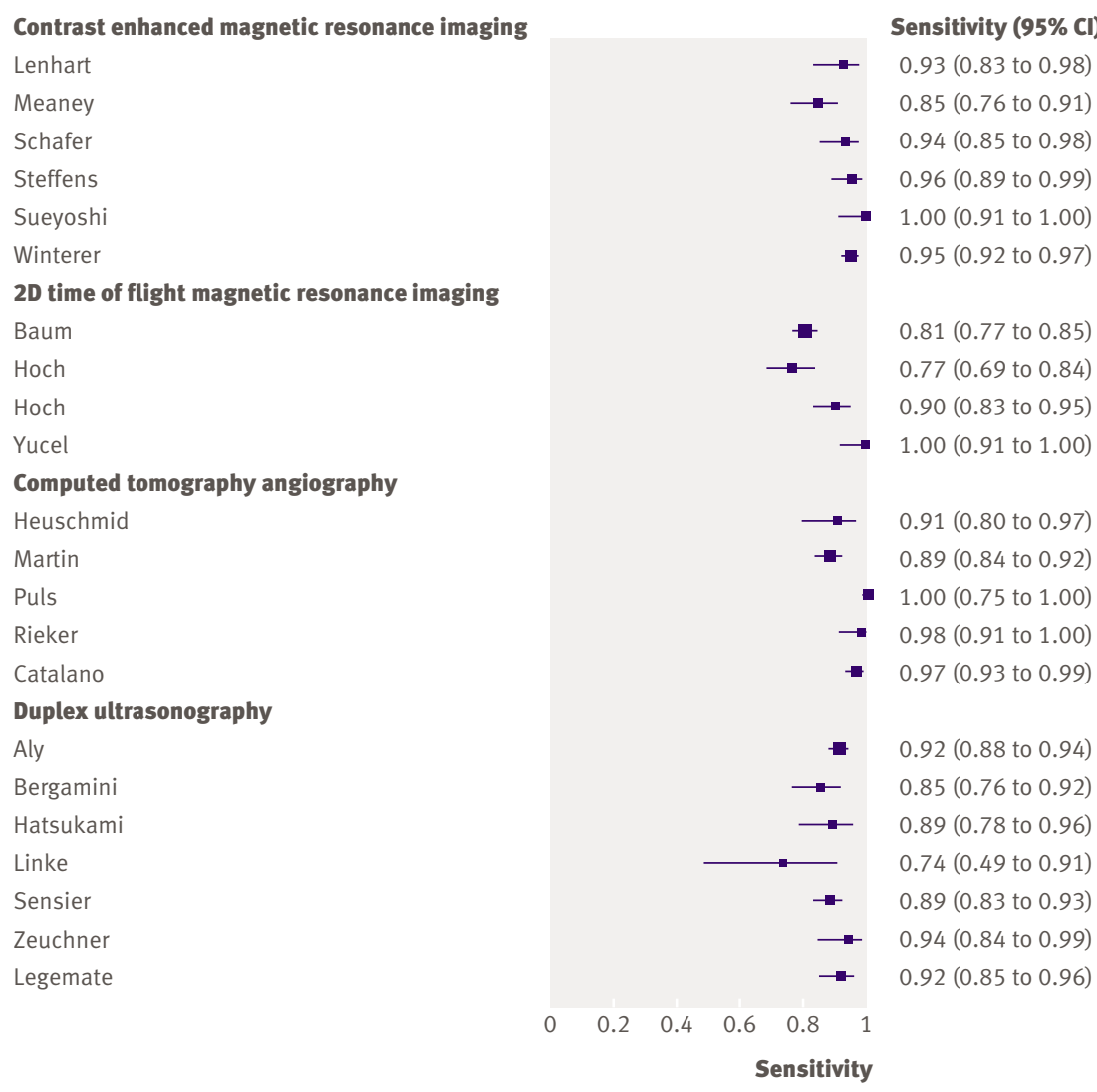

Fig 4 | Sensitivities for the detection of occlusion

of patients who underwent contrast angiography, although the overall proportion who experienced major adverse events was low (severe vascular adverse events: contrast angiography 5\% (1/19 patients); contrast enhanced magnetic resonance angiography $0.5 \%$ (2/435 patients)). There were two deaths: one with contrast angiography and one with contrast enhanced magnetic resonance angiography.

Studies reported adverse events related to the contrast agent for a small proportion of patients in relation to contrast angiography (acute renal failure in 10\% (4/ 42) of patients with baseline chronic renal insufficiency) and contrast enhanced magnetic resonance angiography (acute renal failure: 1\% (3/218) of patients with baseline chronic renal insufficiency; acute change in renal function: 1\% (2/136 patients); severe unspecified adverse events related to contrast agent: up to $1 \%$ (5/641 patients)). In one study, which was specifically designed to evaluate the dose response and safety of one contrast agent (gadofosveset trisodium), ${ }^{\text {w83 }}$ a high proportion of patients $(25 \% ; 59 / 238)$ experienced unspecified adverse events related to the contrast agent after contrast enhanced magnetic resonance angiography.

\section{DISCUSSION}

\section{Key findings}

Contrast enhanced magnetic resonance angiography is the most accurate diagnostic technique for the detection of $(50 \%$ or more) stenosis or occlusion, with most studies reporting sensitivities and specificities of over 90\% (based on a "per segment" rather than "per patient" analysis). Magnetic resonance angiography was associated with the highest proportion of adverse events, although these were generally mild, with the most severe events associated with contrast angiography. The results of three surveys on patients' attitudes showed that patients who had no contraindications for magnetic resonance angiography preferred magnetic resonance angiography to contrast angiography.

The use of computed tomography angiography for the assessment of peripheral arterial disease is a relatively recent development, and its contribution to effective surgical planning remains to be explored. Patients found computed tomography angiography less uncomfortable than contrast angiography or magnetic resonance angiography, and only a few mild adverse events were reported.

The only controlled trial of the effectiveness of imaging procedures, in terms of surgical planning and outcome of patients, found that duplex ultrasonography and contrast angiography were comparable, a result that is seemingly at odds with poor estimates of the diagnostic accuracy for duplex ultrasonography. The sensitivity of duplex ultrasonography seems to be inferior to both contrast enhanced magnetic resonance angiography and computed tomography angiography, which means that duplex ultrasonography may miss some significant stenoses. This may be of particular concern if duplex ultrasonography were to be used to screen patients before surgical planning. Duplex ultrasonography, however, is unlikely to misclassify a whole limb as "normal" and thus inappropriately screen out a patient from further investigation. Fifty per cent of patients expressed no preference between time of flight magnetic resonance angiography or duplex ultrasonography, and those who did generally preferred time of flight magnetic resonance angiography. We had no data on patients' preferences between contrast enhanced magnetic resonance angiography and duplex ultrasonography. Some studies reported minor adverse events associated with duplex ultrasonography - namely, anxiety or minor pain or discomfort during or immediately after the procedure.

The area of leg assessed probably affects diagnostic performance. Contrast enhanced magnetic resonance angiography and duplex ultrasonography were less accurate for detecting stenoses in the foot. There was insufficient evidence to judge computed tomography angiography. The assessment of potential outflow vessels in the foot is known to be problematic ${ }^{9}$ and warrants further research, particularly with respect to newer technologies such as computed tomography angiography. Separate data on calf vessels and foot vessels are required as the inclusion of foot vessels in below knee imaging may lower the accuracy of results.

\section{Strengths and weaknesses of the review}

We conducted extensive literature searches to locate all relevant studies. The possibility of publication bias 
remains a potential problem for all systematic reviews. The extent to which publication bias is an issue for diagnostic studies remains unclear as such studies measure the agreement between the results of the index test and the reference standard, rather than assessing whether there is a significant difference in outcome between an intervention and control group. Studies reporting higher estimates of test performance are more likely to be published, but the extent to which this occurs is unclear. Similarly, tests might not perform as well in the clinical setting as indicated by reports from research studies.

Our review was limited by the lack of high quality, well reported studies. We found only one controlled trial, which used a historical control group that could be subject to bias. Most studies that provided data on diagnostic accuracy had small sample sizes (median 41.5, range 20-183) and reported results on a per segment rather than per patient basis. Our review therefore provides information on the ability of these techniques to detect stenosis within particular arterial segments but not for determining the presence or absence of disease on a per patient or per limb basis. Few included studies reported these data. Analysis by segment also means that the estimates of the $95 \%$ confidence intervals for sensitivity and specificity do not account for the clustering of segments within patients. This would also affect statistical testing of heterogeneity, but given the considerable heterogeneity observed,

Contrast enhanced magneti
Lenhart
Meaney
Schafer
Steffens
Sueyoshi
Winterer
2D time of flight magnetic re
Baum
Hoch
Hoch
Yucel
Computed tomography angi
Heuschmid
Martin
Puls
Rieker
Catalano
Duplex ultrasonography
Aly
Bergamini
Hatsukami
Linke
Sensier
Zeuchner
Legemate
Hot

Specificity $(95 \% \mathrm{Cl})$

- 0.99 (0.96 to 1.00$)$

- 0.97 (0.95 to 0.98$)$

- 1.00 (0.99 to 1.00$)$

- 0.99 (0.98 to 1.00$)$

- 1.00 (0.99 to 1.00$)$

- 0.99 (0.99 to 1.00 )

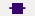

0.85 (0.82 to 0.87$)$

- $\quad 0.96$ (0.93 to 0.98)

- $\quad 0.98$ (0.96 to 1.00$)$

- 0.98 (0.94 to 0.99)

- $\quad 0.99(0.97$ to 1.00$)$

- 1.00 (0.99 to 1.00$)$

- 1.00 (0.98 to 1.00$)$

- 1.00 (0.98 to 1.00$)$

- 0.99 (0.99 to 1.00$)$

$\square$

0.99 (0.99 to 1.00$)$

- $\quad 0.97$ (0.94 to 0.98)

- 0.98 (0.95 to 1.00 )

$\rightarrow \quad 1.00$ (0.97 to 1.00$)$

- $\quad 0.96$ (0.93 to 0.98$)$

- 0.99 (0.97 to 1.00$)$

- 0.99 (0.98 to 1.00$)$

$\begin{array}{llllll}0 & 0.2 & 0.4 & 0.6 & 0.8 & 1\end{array}$

Specificity any conclusions are not likely to be affected. The estimates of specificity derived from this type of study may be raised as increasing the number of segments assessed is likely to increase the number of true negatives.

We did not collect data on variability between observers, although we note that the methods used to ascertain degree of stenosis were not generally well reported and few studies directly measured such variability. This is an important issue in the evaluation of tests that require subjective interpretation, ${ }^{10}$ and further investigation of its effects on estimates of the accuracy of vascular imaging techniques is needed.

The field of vascular imaging research is evolving rapidly, particularly in relation to the use of computed tomography angiography, which is a relatively recent development in the assessment of peripheral arterial disease. We did not find any study investigating the diagnostic accuracy of the new 64 slice computed tomography angiography as this is a very new development. Our results represent the imaging techniques available at the time the primary studies were undertaken and will become out of date as new techniques emerge.

\section{Implications for clinical practice}

From data that reported the accuracy of the imaging tests at assessing arterial segments, rather than the whole limb or areas of the limb, contrast enhanced magnetic resonance angiography seemed to have better overall diagnostic accuracy than computed tomography angiography and duplex ultrasonography, and was preferred by patients over conventional angiography. It might therefore be a viable alternative to conventional contrast angiography for assessing patients with peripheral arterial disease before treatment. We could not identify enough data to assess the effectiveness of the imaging tests in terms of surgical planning and postoperative outcomes. In addition, the lack of data on severity of disease and comorbidities reported by the included studies reduces the generalisability of these findings.

\section{Implications for further research}

Quality assessment highlighted limitations in the quality of methods and reporting of many included studies. Future evaluations of diagnostic tests should follow the STARD guidelines for reporting of diagnostic accuracy studies. ${ }^{112}$ They should also consider reporting results by patient or by limb, as well as by segment, if they would be relevant to clinical practice.

Further research should assess the performance and adverse effects of the imaging tests on different subgroups of patients, particularly those who may be at higher risk of certain adverse events, such as those with diabetes and renal insufficiency. Additional separate data are required regarding the performance of the different imaging tests for assessing calf and foot vessels. The use of newer technologies, such as computed tomography angiography, for the assessment of peripheral arterial disease should be assessed. 


\section{WHAT IS ALREADY KNOWN ON THIS TOPIC}

Severity of disease determines the management strategy for symptomatic lower limb peripheral arterial disease, so detailed assessment of patients is needed before a suitable treatment plan can be developed

Intra-arterial contrast angiography is regarded as the reference standard investigation for the assessment of peripheral arterial disease

\section{WHAT THIS STUDY ADDS}

Contrast enhanced magnetic resonance angiography has better overall diagnostic accuracy than computed tomography angiography or duplex ultrasonography and is generally preferred by patients over conventional contrast angiography

Data on the influence of imaging technologies on the surgical planning and postoperative outcome for patients with peripheral arterial disease are urgently needed. A simple comparison of the accuracy of a technique for defining the degree of stenosis cannot fully assess the ability of a procedure to produce the "vascular road map" as factors such as length and grouping of stenoses are not considered. In addition a comparative diagnostic accuracy study assumes that the result of the reference standard investigation (in this case contrast angiography) is always correct. Therefore, an evaluation with this method can never find that the new technology (index test) gives superior information to that provided by current practice (reference standard).

The most reliable and appropriate method for obtaining comparative data on different testing options would be a randomised controlled trial designed to provide information on the influence of tests on decisions about treatment and outcomes in patients with peripheral arterial disease. Data on health economics could be collected simultaneously. There may be ethical objections to a randomised controlled trial, such as the withholding of an available test, particularly when it is a routine part of assessment of peripheral arterial disease in the institution involved in the study. Such a trial would be difficult because of the refinements in technology over time, the availability of the technologies, and the potentially large sample size required. A large multicentre trial might be necessary.
Contributors: RC (guarantor) was responsible for study selection, data extraction, validity assessment, data analysis, and writing the paper. JB was involved in study selection, data extraction, validity assessment, data analysis, and writing the paper. GC, RA-I, and DC were involved in data extraction, validity assessment, data analysis, and writing the paper. KW devised the search strategy, carried out the literature searches, and wrote the search methods sections of the paper. EB provided advice on technical issues and commented on drafts of the paper. MG provided clinical advice and commented on drafts of the paper. JK provided advice and commented on drafts of the paper. MW provided input at all stages, commented on drafts of the paper, and took overall responsibility for the review.

Funding: Health Technology Assessment Programme (project No 03/07/04). The views and opinions expressed herein are those of the authors and do not necessarily reflect those of the Department of Health.

Competing interests: $\mathrm{EB}$ is now director of a company that undertakes consulting associated with medical imaging research. Neither she nor JK received payment for their contributions to this review. Ethical approval: Not required.

1 Beard J. Chronic lower limb ischaemia. BMJ 2000;320:854-7.

2 Drug treatment of peripheral arterial disease. Bandolier 1996:29-34. www.jr2.ox.ac.uk/bandolier/band29/b29-4.html.

3 Management of peripheral arterial disease (PAD). TransAtlantic InterSociety Consensus (TASC). 2005. www.tasc-pad.org/html/ homepage.htm.

4 Collins R, Cranny G, Burch J, Aguiar-Ibáñez R, Craig D, Wright K, et al. A systematic review of duplex ultrasound, magnetic resonance angiography and computed tomography angiography for the diagnosis and assessment of symptomatic, lower limb peripheral arterial disease. Health Technol Assess 2007;11:1-202.

5 Whiting P, Rutjes A, Reitsma J, Bossuyt P, Kleijnen J. The development of QUADAS: a tool for the quality assessment of studies of diagnostic accuracy included in systematic reviews. BMC Med Res Methodol 2003;3. www.biomedcentral.com/1471-2288/3/25.

6 Moses L, Shapiro D, Littenberg B. Combining independent studies of a diagnostic test into a summary ROC curve: data-analytic approaches and some additional considerations. Stat Med 1993;12:1293-316

7 Zamora J, Muriel A, Abraira V. Meta-DiSc for Windows: a software package for the meta-analysis of diagnostic tests [computer programme]. In: XI Cochrane Colloquium. Barcelona; 2003. www. hrc.es/investigacion/metadisc.html.

8 Loy CT, Irwig L. Accuracy of diagnostic tests read with and without clinical information: a systematic review. JAMA 2004;292:1602-9.

9 Unger EC, Schilling JD, Awad AN, McIntyre KE, Yoshino MT, Pond GD, et al. MR angiography of the foot and ankle. J Magn Reson Imaging 1995;5:1-5.

10 Brealey S, Westwood ME. Are you reading what we are reading? The effect of who interprets medical images on estimates of diagnostic test accuracy in systematic reviews. BrJ Radiol 2007 (in press)

11 Bossuyt PM, Reitsma JB, Bruns DE, Gatsonis CA, Glasziou PP, Irwig LM, et al. Towards complete and accurate reporting of studies of diagnostic accuracy: the STARD initiative. BMJ 2003;326:41-4.

12 Bossuyt PMM, Reitsma JB, Bruns D, Gatsonis C, Glasziou P, Irwig L, et al. The STARD statement for reporting studies of diagnostic accuracy: explanation and elaboration. Ann Intern Med 2003;138: w1-12.

Accepted: 10 April 2007 